\title{
What's an Objective Anyway?
}

\section{Janet L. Eyring}

Teacher trainers (and thus teacher trainees) can often be confused by the array of terminology used for describing goals and objectives in classroom/program planning. With the popularity of learner-centered and task-based learning, is it possible or even necessary to specify objectives when holistic "communicative competence" is the target of instruction? This article acknowledges the controversy among various language experts with regard to the definition and value of objectives. It also confirms the important role that various types of objectives can play in the second language classroom.

Despite the complaints that some students make about writing performance or instructional objectives, as a teacher trainer of ESL methods and curriculum courses, I still believe this is still a valuable endeavor, especially when objectives are used in service to communicative instruction rather than as a reinforcer of traditional learning methods. This position is supported by many professionals in the field (Brown, 1994; Brown, 1995; Nunan, 1988; Wulf \& Schave, 1984; Richards, 1984). Because many discussions of objectives have been confusing and important distinctions have not always been explicitly stated, this article provides clarification by placing objectives clearly in the context of program planning, distinguishing goals from objectives, relating objectives to syllabus design, sequencing objectives in a syllabus, and finally describing performance objectives and discussing their value in a language program. To many reading this article these ideas may seem obvious; however, anyone working in the field for a long time can confirm that students, and even experienced teachers, often have difficulty getting a firm grasp of these concepts and using them for more effective teaching.

\section{The Relationship of Objectives to Program Planning}

Many inexperienced teachers first write "objectives" (either performance objectives or other types) when designing their first lesson plans. However, this seems premature unless some discussion of general program planning preceded such assignments. Various authors have described the curriculum or program design process in different ways, but without exception they seem to include a needs analysis somewhere in the process (Brown, 1995; Richards, 1984; Dubin \& Olshtain, 1986; Taba, 1962). One model of language program design appears in Figure 1.

As can be seen from Figure 1, a needs analysis often precedes the formulation of objectives. The procedure may involve a simple questionnaire or 


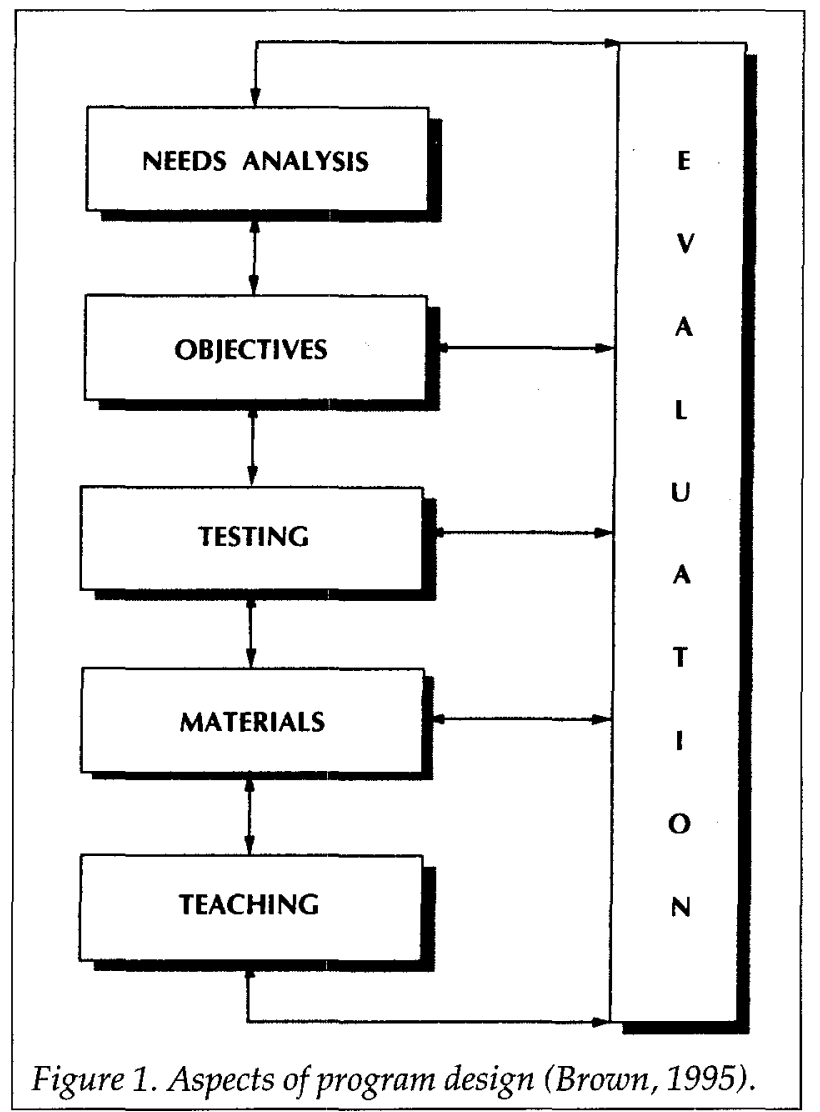

consist of an array of procedures (e.g., observations, examinations, records analysis, checklists, materials analysis) to determine program participants' needs, both subjective (attitudes, preferences, interests) and objective (language proficiency, aptitude, Richards, 1984; Johnson, 1989; Brown, 1995). Other types of information from the teaching context (e.g., testing results, responses to materials and teaching and program evaluation) may also influence what types of objectives are set. By emphasizing the idea early in a teacher training program that objectives must be set according to real needs and real contexts, trainees realize the danger of simply allowing a textbook, not based on any type of analysis of their own program needs, to determine course content.

\section{Goals and Objectives}

Another confusing issue for teachers in training is that they may have no sense of a distinction between goals and objectives. In fact there may be good reason for this misunderstanding, because in practice many program 
descriptions or published guides interchange these two terms, and, in fact, use the term objectives to refer to what technically should be considered goals. What needs to be emphasized is that goals and objectives both specify what participants (usually students, but also teachers, parents, administrators, aides, etc.) in the curriculum do, but objectives are more specific than goals. According to Zais (1976) as cited in Wulf and Schave (1984), goals are "school outcomes," reflecting long-range, general effects. Objectives are "specific learning outcomes as a result of classroom instruction." Gronlund (1991) further refines the notion of objectives by talking about "general instructional objectives" that require a set of "specific learning outcomes" to give a more precise idea of student performance.

At the risk of stating the obvious, I would like to propose the use of inherently transparent labels for the specificity of goals and objectives described. To start, the educator needs to determine what level of specificity is necessary to describe the purposes of a program. If there are only two levels, then Zais' (1976) definition of goal and objective should be used. If there are more than two, then the terms goals, general objectives, and specific objectives should be introduced (see Figure 2). Note that it would not be correct to use the same label for To increase practical writing skills and To address an envelope because the former describes a general outcome after much practice and instruction, whereas the latter describes a more specific outcome after a classroom lesson or two. The adoption of this terminology would reduce confusion in this area.

At first glance one might think that specific objectives describe behaviors generally associated with performance objectives (Vallette \& Disick, 1972). However, performance objectives typically specify four features of a classroom activity: purpose, student behavior, conditions, and criterion. For example, In order to demonstrate comprehension of a short story, students will be given 50 minutes to read "The Lottery" and must respond correctly to 8 out of 10 true/false story-based questions in order to pass. In my opinion, a discussion of these type of objectives should be introduced at a later time because they generally refer to a different level of program design, that is, the specifying of day-to-day classroom lessons, often with reference to methodology, materials, and evaluation. The goals, general objectives, and specific objectives to which I refer often relate to the results of multiple instructional sessions. They are also often stated in the infinitive (e.g., To write a personal letter) or gerund form (e.g., Writing personal letters), but in some cases might be stated as a topic or a content area (e.g., personal letters).

Another well-accepted convention in objectives writing is that objectives, especially specific objectives, need to be stated using verbs that refer to observable behaviors such as write, recite, list, compare rather than verbs more open to interpretation and less easily measured such as know, understand, grasp, believe. Sometimes the objectives are written using several phrases to 


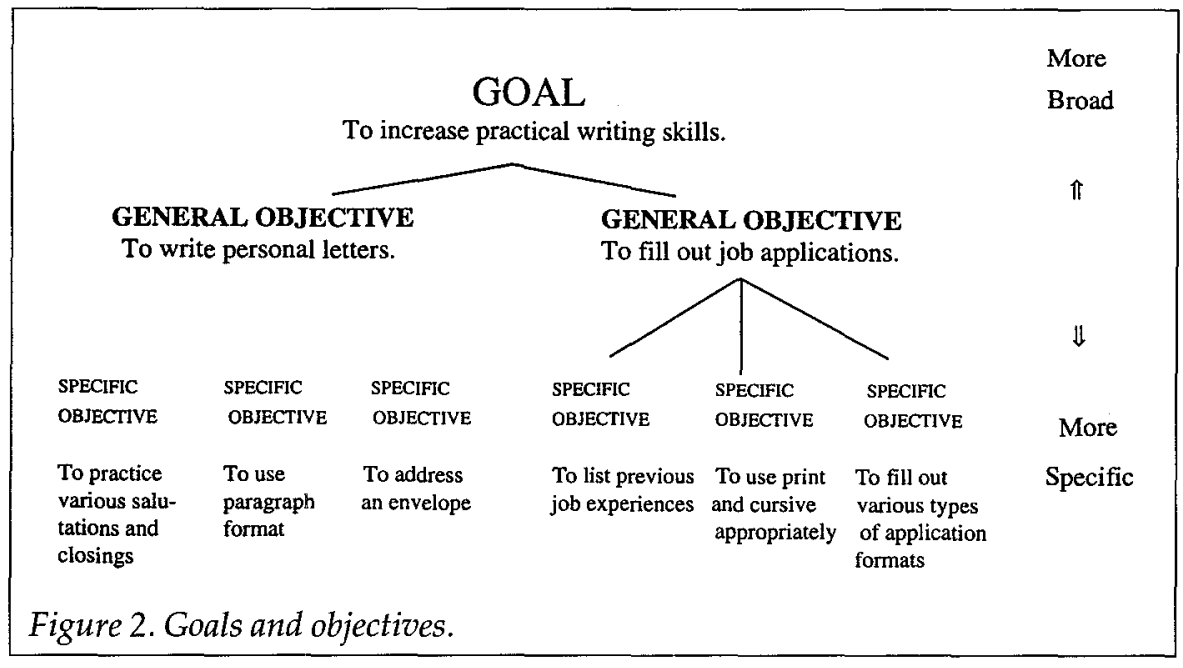

describe the category of language behavior that will be exhibited, for example, Can write on some concrete and familiar topic; Is able to organize and provide some support; Demonstrates limited control of sentence structure and punctuation to indicate sentence boundaries; Often uses inappropriate vocabulary or word forms (Descriptor for Intermediate-Low level in writing in Second Language Proficiency Descriptors, Browning et al., 1995). This type of objective is described in more detail below.

\section{The Syllabus}

With the preceding definition of goals and objectives, it is now much easier to speak of a syllabus. In this case we do not mean the type of syllabus or course outline that professors distribute the first day of class to show readings, course assignments, due dates, and so forth. Rather, a syllabus of a language program is a taxonomy or categorization of goals and objectives. However, the taxonomy is not a random list, and depending on the particular needs of a group of learners, it provides, as McKay (1980) states, "a focus for what should be studied, along with a rationale for how that content should be selected and ordered" (p. 73). In this section I deal specifically with this idea of focus and save discussion of selection and ordering for the following section.

Are the goals and objectives in a syllabus of the same type? Richards (1984) sheds some light on this matter with his discussion of three types of objectives: proficiency, process, and content. These terms could also be useful in describing three broad general types of syllabus (Appendixes A and B).

The first type, the proficiency-related type, enjoys wide acceptance in foreign language teaching as evidenced by the American Council of Foreign Language Teachers (ACTFL) Guidelines and possible future acceptance in 
ESL teaching (California Pathways, Second Language Proficiency Descriptors, Browning et al., 1995) and presents a particular view about the nature of language learning. The focus of this list of objectives is the description of the type of language that a student should be able to produce in listening, speaking, reading, and writing and culture as a result of communicative language use inside (and outside) of the classroom. These objectives theoretically need not be tied to any program of study, but seek to describe normal language development of someone acquiring facility with function, context, and accuracy in a language. Because of the more vague or broad nature of these objective statements, they might more precisely be called goals, but they are statements of purpose as earlier described. ${ }^{1}$

The second type of objective that Richards (1984) described is the processrelated objective. He defined these types of objectives as "specifications of processes which underlie fluency in specific skill areas." This type of syllabus would be favored by proponents of skill-based programs, where holistictype skills are being developed (e.g., improving listening comprehension, increasing reading speed, generating ideas for writing). This is also the type of objective that syllabus detractors (or anti-syllabus proponents) hesitate to describe, because language learning is viewed as requiring repeated and varied practice of language for real purposes and, therefore, is not entirely predictable. Task-based, project work, and fully communicative syllabi (as described by Yalden, 1983) are three types that specify objectives in terms of processes (e.g., Negotiating what to study, researching an historical figure, reading a train schedule and planning a trip). These types of objectives are meant to describe processes that can transfer to broader situations (e.g., negotiating a business deal, researching any topic of interest, reading any type of chart and applying the information to some other activity).

The third type of objective is the content-based objective. This objective refers to linguistic or communicative content and is the most widespread in ESL/EFL programs today. This content can be described as grammar, functions, survival situations, popular topics, literature, business/medicine/ science and correspondingly relates to many of the most popular syllabi in use: for example, the structural syllabus, the functional syllabus, the competence-based syllabus, the literature-based syllabus, and the English for Specific Purposes (ESP) syllabus. Although some of these syllabi are quite modern, their main focus is product-oriented - to promote the learning of content. The later specification of program features may include process elements or even acknowledge a universal development of proficiency, but as a main organizing strand, the content-based syllabus is a means-end type of syllabus. $^{2}$

The reason for presenting these three types of objectives (proficiency, process, and content) as if they were mutually exclusive is to emphasize that different major focuses may be selected by language educators to guide a 
program. However, it is important to note that most language curriculum experts see the combining of these purposes as more common than not. Yalden (1983) proposed that the focus of instruction might change from the beginning to advanced levels with content-based (more structured) syllabuses having higher priority at the beginning levels, and process-based (more communicative) syllabuses having higher priority at the advanced levels. Dubin and Olshtain (1986) also spoke of the intertwining of syllabus types as strands, where one may take precedence over another. For example, a syllabus may include topics, skills, and structural strands (see Figure 3).

Although Brown (1995) considers topically based syllabi and situationally based syllabi as separate categories, it is clear that simply listing topics or situations is not a syllabus in the sense described here. In fact a topic such as "the garden" or a situation like "in the garden" could be quite ambiguous because it could easily imply various types of objectives and thus more than one type of syllabus (e.g., To keep a garden journal [process-related objective; project work syllabus] or Using the present tense to describe planting cycles and growing methods in a garden [content-based objective; structural syllabus]). The curriculum designer must realize that when lists of topics or situations constitute the only strand of a syllabus, the focus or theoretical orientation, as described by McKay (1980), is not entirely clear without further specification.

\section{Sequencing Objectives in the Syllabus}

With the types of objectives and accompanying syllabi defined, the teacher trainer now needs to help trainees understand how to sequence objectives. Of course, with proficiency-related objectives, this has already been done where levels have been described from Novice to Superior (Omaggio, 1986). With other types of objectives, different criteria can be used to decide how objectives should be ordered at the beginning through advanced levels. Some criteria that have been suggested are complexity, cognitive demand, frequency of use, immediacy of need, and order of acquisition. In some cases one criterion might suggest that one objective is ordered before another, but a competing criterion would contradict the first decision. In this case, the educator must make a judgment call. As an example, consider the two items from a functional syllabus-expressing gratitude and expressing necessity. On the one hand, if immediacy of need is considered most important, perhaps newcomers to an English-speaking country would need to express thanks before they would need to express what they want. However, if difficulty of the item is considered in terms of grammar, perhaps instruction in a statement such as "I need an apartment" should precede instruction in the grammar for "Thank you for helping me" The educator can make a choice based on his or her own intuition in this case or ensure that recycling occurs in the syllabus and objectives that appear at one level recur at more 


\begin{tabular}{|lll|}
\hline Topics & Skills & Structures \\
\hline Turning Points & Sharing personal experiences & Verb Tense \\
Holidays and Celebrations & Giving presentations & Adjectives \\
Hobbies & Teaching a process & Connectors \\
Education & Conducting interviews & Modal Verbs \\
Male and Female Roles & Debating issues & Complementation \\
\hline \multirow{2}{*}{ Figure 3. Example of intertwined objectives in a speaking course. } \\
\hline
\end{tabular}

advanced levels at increasing levels of complexity. In the preceding case, the educator could simply teach "thank you" at the beginning level and save the gerund structure ("Thank you for helping me.") for later in the syllabus.

Quite a bit has been written about the need to order objectives according to cognitive, affective, and psychomotor development. Bloom (1956), Krathwohl et al. (1964), and Harrow (1972) designed taxonomies that could assist teachers in ordering objectives in a syllabus. Although these were designed for instructors in general education, they can also apply to ESL educators. Using an example from the cognitive domain, it could be said that interpreting something is generally more cognitively difficult than describing something. In the affective domain verifying something is more challenging than pointing to something. Finally, in the psychomotor domain, arranging something requires greater psychomotor skills than simply detecting something. The responsible ESL educator should consult such lists in making decisions about sequencing ESL objectives from more simple to more complex.

\section{Performance Objectives}

Finally, what are performance objectives, and are they still important to state? As mentioned above, a performance objective contains four parts: a purpose, a student behavior, conditions, and a criterion (Valette \& Disick, 1972). Taking the general objective of "writing a personal letter" and the specific objective of "practicing various salutations and closings" as a starting point, several performance objectives would need to be written in order to describe the many activities and accompanying student behaviors needed to show that a student has learned to use an appropriate salutation and closing in a letter. Three examples in Figure 4 illustrate how activities might be graded so that an elementary school student is finally able to demonstrate his or her mastery of just one general objective

For the beginning teacher (and sometimes the experienced teacher), writing objectives concisely and correctly can be a challenge. To illustrate this, a beginning teacher's first attempt at writing a performance objective follows:

To display knowledge and ability to retain correct use of count-noncount nouns. Students will be able to complete a short exercise. 
Goal: To increase practical writing skills

General Objective: To write personal letters

Specific Objective: To practice various salutations and closings

Performance Objective \#1: In order to increase understanding of the variety of ways to open and close a personal letter, the student will skim 10 personal letters on a handout and circle the salutation and closing on each (e.g., Hi, Howdy, See ya, Till later, etc.). In order to show mastery, students must circle all 20 of the items in five minutes.

Performance Objective \#2: To demonstrate knowledge of how to insert appropriate openings and closings to personal letters, the student will insert the correct words in blanks provided before and after the body of short personal letters. To pass, the student must provide an appropriate word or phrase in 8 out of 10 blanks.

Performance Objective \#3: To practice writing appropriate openings and closings to personal letters, the student will write a short note to a friend inviting him or her for an afternoon visit. In order to pass, the student must use both an appropriate opening or closing to the letter. The body of the letter will not be graded.

Figure 4. Understanding performance objectives.

Several problems can be noted here. The activity does not clearly correspond to the purpose, the conditions and criterion are not stated, and the reader does not have a clear idea of what it is the students will do. Stated more appropriately, the objective might read:

In order to recognize and use noncount nouns, students will be given 15 minutes to form dyads and write five true and false statements about a set of noncount nouns (e.g., luggage, furniture, money, research, work). They will then regroup with a second pair who were given a different set of nouns and the same task. One pair will read their sentences while the other pair guesses if the sentences are true or false. The other pair will do the same (e.g., The furniture in Lisa's apartment is modern.) Students will pass if they interact with each other for approximately 20 minutes and they use appropriate verb agreement with the noncount nouns approximately $80 \%$ of the time.

On reading a fully stated objective, it is not hard to understand why a beginning teacher has some difficulty writing such objectives. He or she does not have the full array of teaching experience that would make the writing of objectives automatic. For example, she may not be entirely familiar with various methods (e.g., Silent Way, Audiolingual Method, Natural Approach, Counseling Learning, Problem-Posing), procedures (e.g., jazz chants, dictocomps, cloze exercises, jigsaw tasks), materials (songs, texts, charts), and management options (e.g., dyads, whole class, small group) to specify an activity clearly. In addition, she may not understand that certain activities are best described as expressive objectives (Vallete \& Disick, 1972) in which 
the conditions and criterion are stated in general or approximate terms (see approximately and appropriate in the revised example above) or not at all.

This difficulty with writing objectives is only one of the reasons that performance objectives have been under attack for decades. Schwab (1996) stated that objectives also "anatomize matters that may be of great importance into bits and pieces which, taken separately, are trivial or pointless." Another reason is that they have appeared to be constricting in the classroom to the experienced teacher. By explicitly stating behaviors, conditions, and criteria, no room is left for the flexibility or creativity that often occurs during in-flight decision-making. It is also true that the practicing teacher, under tremendous time pressures, rarely has time to write a full array of performance objectives for every class he or she plans to teach, even if he or she wanted to.

Despite these criticisms, performance objectives can be a useful teacher training tool because they require new and less experienced teachers to think about major program goals and relate these to what they are doing in the classroom (e.g., determine the purpose of an activity, define key aspects of an activity, estimate a time frame, and know whether students have been successful). They are essential for planning 10-15-minute teaching demonstrations in preservice programs, where teachers must be held strictly accountable for what they do because of the limited time available for doing such oral demonstrations during class time. They can also be useful for any type of individualized programmed instruction materials or distance learning materials where the input of a live instructor may be limited.

\section{Conclusion}

This article underlines the importance of specifying objectives in language instruction based on a needs analysis. Depending on the level of specificity desired, either goals, general objectives, or specific objectives can be stated. Program designers tend to state goals with accompanying general objectives, whereas classroom teachers often rely mostly on specific objectives for planning classroom teaching. Program planners specify syllabi that contain lists of objectives of three general types (proficiency, process, and content). Depending on the type of program, one or more types of objectives may be intertwined when describing the purposes of a program. Performance objectives in modern language classrooms, on the other hand, seem to be limited to particular settings such as preservice training, teaching demonstrations, and programmed instruction. In sum, the statement of all types of objectives is valuable for the teacher, as well as for the students, as a guide for learning. By encouraging student input in setting goals and objectives and revising these along the way, students become coparticipants in the learning process, which is the key to motivation in successful language learning. 


\section{Notes}

${ }^{1}$ This proposition may be unpopular to those who strenuously deny that the proficiency guidelines are not a syllabus. However, in practice the guidelines do serve to focus instruction (albeit broadly) in the classroom, which is the nature of a syllabus as earlier defined. As Richards (1984) states, the Foreign Service Institute (FSI) Oral Proficiency scale, which is similar to the ACTFL scale, "can be used to not only assess proficiency for diagnostic or placement purposes but also to establish levels of proficiency as program objectives." Richards adds, however, that these proficiency descriptions "complement rather than replace the use of program objectives."

${ }^{2}$ This definition of content-based may contradict the framework developed by Brinton, Snow, and Wesche (1989) because of the basic purposes associated with the three so-called content-based syllabi. The theme-based syllabus may in fact be more closely related to the process-based syllabus, because its main purpose is to reinforce language skills, with content creating interest for this purpose. The other two types, sheltered and adjunct, more clearly have a major purpose to teach content to students with the development of language skills as a positive side effect.

\section{The Author}

Janet Eyring is the TESOL Coordinator in the Department of Foreign Languages and Literatures at California State University, Fullerton. She has been an ESL teacher and ESL teacher trainer for the past 18 years.

\section{References}

Bloom, B.S. (1956). (Ed.). Taxonomy of educational objectives: Handbook I, Cognitive Domain. New York: David McKay.

Brinton, D., Snow, M.A., \& Wesche, M. (1989). Content-based second language instruction. New York: Newbury House/Harper \& Row.

Brown, H.D. (1994). Teaching by principles: An interactive approach to language pedagogy. Englewood Cliffs, NJ: Prentice Hall Regents.

Brown, J.D. (1995). The elements of language curriculum. Boston, MA: Heinle \& Heinle.

Browning, G. et al. (1995). California pathways: The second language student in public high schools, colleges and universities. ESL Intersegmental Project.

Dubin, F., \& Olshtain, E. (1986). Course design: Developing programs and materials for language learning. Cambridge: Cambridge University Press.

Gronlund, N. (1991). How to write and use instructional objectives. New York: Macmillan

Harrow, A.J. (1972). A taxonomy of the psychomotor domain. New York: David McKay.

Johnson, R.K. (1989). The second language curriculum. Cambridge: Cambridge University Press.

Krathwohl, D.R. et al. (1964). Taxonomy of educational objectives: Handbook II, affective domain. New York: David McKay.

McKay, S. (1980). Towards an integrated syllaus. In K. Croft (Ed.), Readings in English as a second language (pp. 72-84). Cambridge, MA: Winthrop.

Nunan, D. (1988). Syllabus design. Oxford: Oxford University Press.

Omaggio, A. (1986). Teaching language in context: Proficiency-oriented instruction. Boston, MA: Heinle \& Heinle.

Johnson, R.K. (1989). (Ed.). The second language curriculum. Cambridge: Cambridge University Press.

Richards, J. (1984). Language curriculum development. RELC Journal, 15(1).

Schwab, J. (1996). The practical 4: Something for curriculum professors to do. In E. Hollins (Ed.), Transforming curriculum for a culturally diverse society. Mahwah, NJ: Erlbaum.

Taba, H. (1962). Curriculum development: Theory and practice. New York: Harcourt, Brace and World. 
Valette, R., \& Disick, R. (1972). Modern language performance objectives and individualization: A handbook. NewYork: Harcourt Brace Jovanovich.

Wulf, K., \& Schave, B. (1984). Curriculum design: A handbook for educators. Glenview, IL: Scott, Foresman.

Yalden, J. (1983). The communicative syllabus: Evolution, design and implementation. Oxford: Pergamon Press.

Zais, R.S. (1976). Curriculum: Principles and foundations. New York: Thomas Y. Crowell.

\section{Appendix A: Goals And Objectives as Related to Language Syllabuses}

Proficiency-related Goals/Objectives

Purpose: To achieve sustained, creative, appropriate, interactive language behavior

Process-related Goals/Objectives

Purpose: To learn how to learn

Content-related Goals/Objectives

Purpose: To learn content
Proficiency-based Syllabuses/Objectives

ACTFL Guidelines

Second Language Proficiency Descriptors

Process-based Syllabuses

Skills-based Syllabus

Task-based Syllabus

Project Work Syllabus

Fully Communicative Syllabus

Theme-based Syllabus

Content-based Syllabuses

Structural Syllabus

Functional Syllabus

Competence-based Syllabus

Literature-based Syllabus

English for Specific Purposes Syllabus

Sheltered/SDAIE Syllabus

Adjunct Syllabus

\section{Appendix B: Sample Objectives.}

\section{Proficiency-related Objectives}

Novice-Low Oral production consists of isolated words and perhaps a few high-frequency phrases. Essentially no functional communicative ability.

Novice-Mid Oral production continues to consist of isolated words and learned phrases within very predictable areas of need, although quality is increased. Vocabulary is sufficient only for handling simple, elementary needs and expressing basic courtesies. Utterances rarely consist of more than two or three words and show frequent long pauses and repetition of interlocutor's words. Speaker may have some difficulty producing even the simplest utterances. Some Novice-Mid speakers will be understood only with great difficulty. 
Novice-High Able to satisfy partly the requirements of basic communicative exchanges by relying heavily on learned utterances, but occasionally expanding these through simple recombinations of their elements. Can ask questions or make statements involving learned material. Shows signs of spontaneity, although this falls short of real autonomy of expression. Speech continues to consist of learned utterances rather than of personalized, situationally adapted ones. Vocabulary centers on areas such as basic objects, places, and most common kinship terms. Pronunciation may still be strongly influenced by first language. Errors are frequent and, in spite of repetition, some Novice-High speakers will have difficulty being understood even by sympathetic interlocutors. (Omaggio, 1986).

\section{Process-related Objectives}

\section{Micro-Skills: Academic Listening}

1. Ability to identify purpose and scope of lecture.

2. Ability to identify topic of lecture and follow topic development.

3. Ability to identify relationships among units within discourse (e.g., major ideas, generalizations, hypotheses, supporting ideas, examples).

4. Ability to identify role of discourse markers in signaling structure of a lecture (e.g., conjunctions, adverbs, gambits, routines).

5. Ability to infer relationships (e.g., cause, effect, conclusion).

6. Ability to recognize key lexical items related to subject/topic.

7. Ability to deduce meanings of words from context.

8. Ability to recognize markers of cohesion.

9. Ability to recognize function of intonation to signal information structure (e.g., pitch, volume, pace, key).

10. Ability to detect attitude of speaker toward subject matter (Richards, 1987).

\section{Content-related Objectives:}

Checklist I: Language Functions

\section{Factual information}

1.1 identifying

1.2 reporting through description

1.3 reporting through narration

1.4 correcting

2 Argument

2.1 expressingagreement/disagreement

2.2 confirmation/denial

3. Likelihood

3.1 expressing possibility/impossibility

3.2 expressing probability/improbability

3.3 expressing logical conclusions (deduction

3.4 expressing prediction and predictability (Yalden, 1984). 